Brazilian Journal of Microbiology (2009) 40: 693-700

ISSN 1517-8382

\title{
IDENTIFICATION, ANTIMICROBIAL RESISTANCE AND GENOTYPIC CHARACTERIZATION OF ENTEROCOCCUS SPP. ISOLATED IN PORTO ALEGRE, BRAZIL
}

\author{
Eduardo André Bender ${ }^{1 *}$, Ana Lúcia Peixoto de Freitas ${ }^{2}$, Keli Cristine Reiter ${ }^{2}$, Larissa Lutz ${ }^{3}$, Afonso Luís Barth ${ }^{2,3}$ \\ ${ }^{1}$ Programa de Pós-Graduação em Ciências Farmacêuticas, Faculdade de Farmácia, Universidade Federal do Rio Grande do \\ Sul, Porto Alegre, RS, Brasil; ${ }^{2}$ Departamento de Análises, Faculdade de Farmácia, Universidade Federal do Rio Grande do \\ Sul, Porto Alegre, RS, Brasil; ${ }^{3}$ Unidade de Microbiologia e Biologia Molecular, Serviço de Patologia Clínica, Hospital de \\ Clínicas de Porto Alegre, Porto Alegre, RS, Brasil.
}

Submitted: September 08, 2008; Returned to authors for corrections: October 14, 2008; Approved: May 03, 2009.

\begin{abstract}
In the past two decades the members of the genus Enterococcus have emerged as important nosocomial pathogens worldwide. In the present study, we evaluated the antimicrobial resistance and genotypic characteristics of 203 Enterococcus spp. recovered from different clinical sources from two hospitals in Porto Alegre, Rio Grande do Sul, Brazil. The species were identified by conventional biochemical tests and by an automated system. The genetic diversity of $E$. faecalis presenting high-level aminoglycoside resistance (HLAR) was assessed by pulsed-field gel electrophoresis of chromosomal DNA after SmaI digestion. The E. faecalis was the most frequent specie (93.6\%), followed by E. faecium (4.4\%). The antimicrobial resistance profile was: $2.5 \%$ to ampicillin, $0.5 \%$ to vancomycin, $0.5 \%$ teicoplanin, $33 \%$ to chloramphenicol, $2 \%$ to nitrofurantoin, $66.1 \%$ to erythromycin, $66.5 \%$ to tetracycline, $24.6 \%$ to rifampicin, $30 \%$ to ciprofloxacin and $87.2 \%$ to quinupristin-dalfopristin. A total of $10.3 \%$ of the isolates proved to be HLAR to both gentamicin and streptomycin (HLR-ST/GE), with $23.6 \%$ resistant only to gentamicin (HLR-GE) and 37.4\% only to streptomycin (HLR-ST). One predominant clonal group was found among E. faecalis HLR-GE/ST. The prevalence of resistance among beta-lactam antibiotics and glycopeptides was very low. However, in this study there was an increased number of HLR Enterococcus which may be spreading intra and inter-hospital.
\end{abstract}

Key words: Enterococcus, resistance, HLAR, PFGE

*Corresponding Author. Mailing address: Rua Vicente da Fontoura 2895/401, Bairro Rio Branco, Porto Alegre, RS, Brazil. CEP 90640-003. Phone:

+512103-2861. Email: eabender@hotmail.com 
Bender, E.A. et al.

\section{INTRODUCTION}

Enterococci have increasingly emerged as a cause of serious nosocomial and community-acquired infections, including bacteremia and endocardites $(1,19)$. Bactericidal antimicrobial activity, necessary for the treatment of enterococcal infections, is usually obtained by the synergistic combination of a cell-wall active agent, such as a $\beta$-lactams or a glycopeptide, with an aminoglycoside, such as gentamicin or streptomycin $(3,25)$. Several studies have shown increasing resistance of enterococci to antimicrobial agents such as $\beta$-lactams, high-level aminoglycosides and more recently to glycopeptides $(11,24,25)$.

The emergence of resistance to glycopeptides among Enterococcus spp (GRE) has alarmed the scientific community as there is just a very few treatment options for the GRE. Moreover, the fear exists that Staphylococcus aureus may import the van genes from Enterococcus as this was already demonstrated in in vitro experiments $(11,22)$. Colonization of patients in hospital settings by resistant enterococci has been associated to the microorganism spread from other patients and/or from the environment as preventive measures to contain their spread may be of little success $(1,3,24)$.

The use of molecular techniques such as pulsed-field gel electrophoresis (PFGE) for analysis of the occurrence of different clonal groups of Enterococcus presenting high-level aminoglycoside resistance in Brazilian hospitals has been consistently reported $(7,12,18)$. Nevertheless, there is only scanty information about the routes of transmission of resistant enterococci in hospitals from southern Brazil. Thus, this study aims to update epidemiological data on the occurrence of this microorganism in the city of Porto Alegre by carrying out tests for identification of species, analysis of antimicrobial susceptibility and molecular typing by PFGE.

\section{MATERIALS AND METHODS}

\section{Bacterial isolates}

A total of 203 enterococcal isolates recovered from patients receiving medical care in two different hospitals (Hospital de Clínicas de Porto Alegre and Hospital São Lucas da PUC) located at Porto Alegre, southern Brazil, were collected during the period from december 2006 to march 2007. The isolates were obtained from urine (131), secretions (38) blood (18), catheter (4) and other sources (10). Only one isolate per patient was included in the study. All isolates were stored at $-80^{\circ} \mathrm{C}$ in $\mathrm{BHI}$ broth plus $20 \%$ glycerol.

\section{Identification of enterococcal isolates}

Identification of the isolates to the genus level was performed according to: reaction on Gram staining; cellular morphology; growth and blackening of bile-esculin agar, growth in the presence of $6.5 \% \mathrm{NaCl}$; absence of catalase; and presence of pyrrolidonyl arylamidase (PYR). Identification to species level was performed by a panel of biochemical tests $(9,10)$. Species were also identified by the VITEK 2 system (software version 1.02) (BioMerieux) according to the manufacturer's recommendations.

\section{Susceptibility testing}

Antibiotic susceptibility studies were performed by disc diffusion method (Kirby-Bauer) according to the Clinical and Laboratory Standard Institute (CLSI 2007) (5) for the following antibiotics: ampicillin, vancomycin, teicoplanin, rifampicin, erythromycin, tetracycline, cloranfenicol, ciprofloxacin, quinupristin-dalfopristin, nitrofurantoin (Oxoid Ltd, Basingstoke, UK). High level aminoglycoside resistance was determined by two different methods: standard agar screening and disc diffusion. Standard agar screening for HLAR was carried out on Mueller-Hinton agar plates (Oxoid 
Ltd, Basingstoke, UK) with either $500 \mu \mathrm{g} / \mathrm{mL}$ gentamicin (Oxoid Ltd) or $2000 \mu \mathrm{g} / \mathrm{mL}$ streptomycin (Oxoid Ltd). The disc diffusion screening method was performed on MuellerHinton agar (BBL Microbiology Systems) using discs with $120 \mu \mathrm{g} / \mathrm{mL}$ of gentamicin and $300 \mu \mathrm{g} / \mathrm{mL}$ of streptomycin (Oxoid Ltd). The correlation between the results of the above methods was determined by the kappa coefficient (SPSS V.15.0).

Isolates were tested for $\beta$-lactamase production by the chromogenic cephalosporin (nitrocefin) disk method (Becton Dickinson Diagnostic Systems, Sparks, Maryland, USA). Enterococcus faecalis ATCC 29212 and Staphylococcus aureus ATCC 25923 were used as quality control strains for all tests of susceptibility.

\section{DNA extraction and restriction fragment analysis by PFGE}

Chromosomal DNA was obtained as described by Kaufmann (15). Purified DNA was digested with the restriction enzyme SmaI (GIBCO BRL, New York) and separated by PFGE in 1\% agarose gels, using a CHEF-DRII system (Bio-Rad Laboratories, Richmond, Calif.). The pulse time was increased from 5 to $35 \mathrm{~s}$, over 22 hours at $5,9 \mathrm{~V} / \mathrm{cm}$ at $11^{\circ} \mathrm{C}$ and a $120^{\circ}$ angle. Lambda ladder of $48,5 \mathrm{~Kb}$ concatamers (New England BioLabs, Beverly, MA, UK) were used as molecular weight markers. Gels were stained with ethidium bromide and photographed under UV light. Analysis of DNA restriction profiles was performed by visual inspection according to Tenover et al. (23).

\section{RESULTS}

It was possible to identify 5 species among the 203 isolates of Enterococcus in our study: E. faecalis (93.6\%), E. faecium (4.4\%), E. casseliflavus (1\%), E. gallinarum $(0.5 \%)$ and E. hirae $(0.5 \%)$.

The majority of isolates were highly susceptible to several antibiotics (ampicillin, vancomycin, teicoplanin, and nitrofurantoin) by the disc diffusion method. High resistance rates were observed only to erythromycin, tetracycline and quinupristin-dalfopristin (Table 1). It is of note that only five enterococci were resistant to ampicillin and four of them were identified as E. faecium. As expected, the presence of $E$. faecalis resistant to this $\beta$-lactam antibiotic was very rare in our study. None of the isolates displayed $\beta$-lactamase activity.

We found only three isolates non-susceptible to vancomycin: one isolate, which was fully resistant to vancomycin, was identified as E. faecalis; and the other two isolates, with intermediary resistance to vancomycin, were identified as E. casseliflavus and E. gallinarum.

High-level resistance to gentamicin or streptomycin was detected by the disc diffusion in $23.6 \%$ and $37.4 \%$ of isolates, respectively. Combined high-level streptomycin and gentamicin resistance (HLR-GE/ST) was detected in 10.3\% of isolates. E. faecium isolates had a higher rate of combined resistance (streptomycin and gentamicin) than the other species. Excellent correlation was observed between the high-level disc test and the agar screening test in the detection of HLAR (Kappa coefficient was 0.89).

It was possible to compare the resistance rates of HLAR and non-HLAR isolates to other antibiotics and the HLAR proved to be more resistant to all non- $\beta$-lactams.

The genetic profile of 17 isolates of E. faecalis HLRGE/ST was examined and we found the existence of 8 isolates with identical profile (clone A). Five isolates proved to be highly correlated to the clone A and were considered to belong to the this major clonal group (Fig. 1). The other 4 isolates were all unrelated. 
Bender, E.A. et al.

Table I. Antimicrobial susceptibility profile according to disc diffusion method among 203 enterococcal isolates in two hospitals in the city of Porto Alegre, Brazil.

\begin{tabular}{|c|c|c|c|}
\hline Antimicrobial agents & $\begin{array}{c}\text { Susceptible } \\
\text { N (\%) }\end{array}$ & $\begin{array}{c}\text { Intermediate } \\
\text { n (\%) }\end{array}$ & $\begin{array}{c}\text { Resistant } \\
\text { n (\%) }\end{array}$ \\
\hline Ampicillin & $198(97,5)$ & $\mathrm{NA}^{\mathrm{a}}$ & $5(2,5)$ \\
\hline Streptomycin (HLR-St) ${ }^{b}$ & $130(64,0)$ & $0(0)$ & $73(36,0)$ \\
\hline Gentamicin (HLR-Ge) ${ }^{\mathrm{c}}$ & $156(76,8)$ & $2(1,0)$ & $45(22,2)$ \\
\hline Vancomycin & $200(98,5)$ & $2(1,0)$ & $1(0,5)$ \\
\hline Teicoplanin & $202(99,5)$ & $0(0)$ & $1(0,5)$ \\
\hline Cloranfenicol & $131(64,5)$ & $5(2,5)$ & $67(33,0)$ \\
\hline Nitrofurantoin & $195(96)$ & $4(2,0)$ & $4(2,0)$ \\
\hline Erythromycin & $15(7,4)$ & $62(30,5)$ & $126(62,1)$ \\
\hline Tetracycline & $68(33,5)$ & $4(2,0)$ & $131(64,5)$ \\
\hline Rifampicin & $71(35,0)$ & $82(40,4)$ & $50(24,6)$ \\
\hline Ciprofloxacin & $114(56,2)$ & $28(13,8)$ & $61(30,0)$ \\
\hline Quinupristin-dalfopristin ${ }^{\mathrm{d}}$ & $12(5,9)$ & $14(6,9)$ & $177(87,2)$ \\
\hline
\end{tabular}

${ }^{\text {a }}$ Not applicable

${ }^{\mathrm{b}}$ HLR-St: high-level resistance to streptomycin

${ }^{\mathrm{c}}$ HLR-Ge: high-level resistance to gentamicin

${ }^{\mathrm{d}}$ High difference of resistance among enterococci species: E.faecium $11.1 \%$ resistante and E.faecalis $91 \%$ of resistance

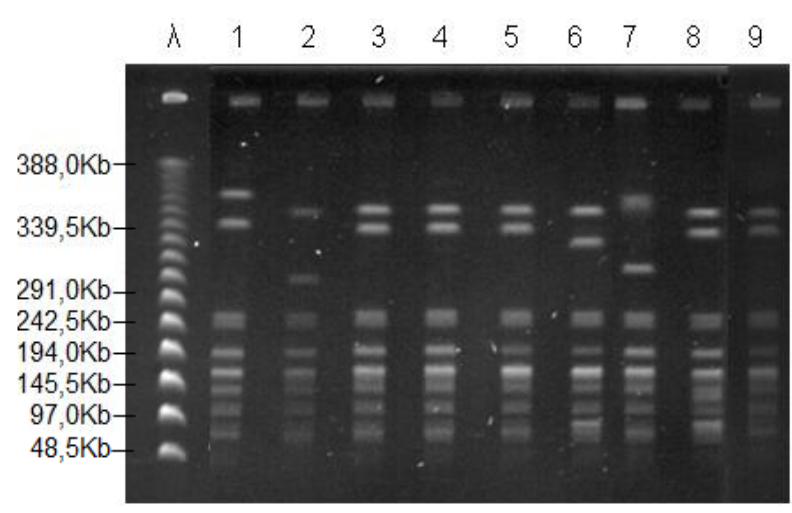

Figure 1. PFGE profiles of SmaI-digested chromosomal DNA of HLR-GE/ST Enterococcus faecalis isolates belonging to major clonal group A. $\lambda$ lambda phage DNA markers; lanes 1-7: isolates from HSL; lanes 8-9: isolates from HCPA.

We also analyzed 18 isolates of E. faecalis presenting high-level resistance only to gentamicin (HLR-GE) by PFGE. No predominant clonal group was found among HLR-GE as 11 clones were identified. Noteworthy one clone (representing only one isolate) was highly related to the predominant clone A of HLR-GE/ST (subclone A6) (Fig. 2).

The only vancomycin-resistant Enterococcus isolate (VRE) identified in this study was also resistant to ampicillin, teicoplanin, HLR-GE/ST and presented a unique PFGE profile (Fig. 2). 


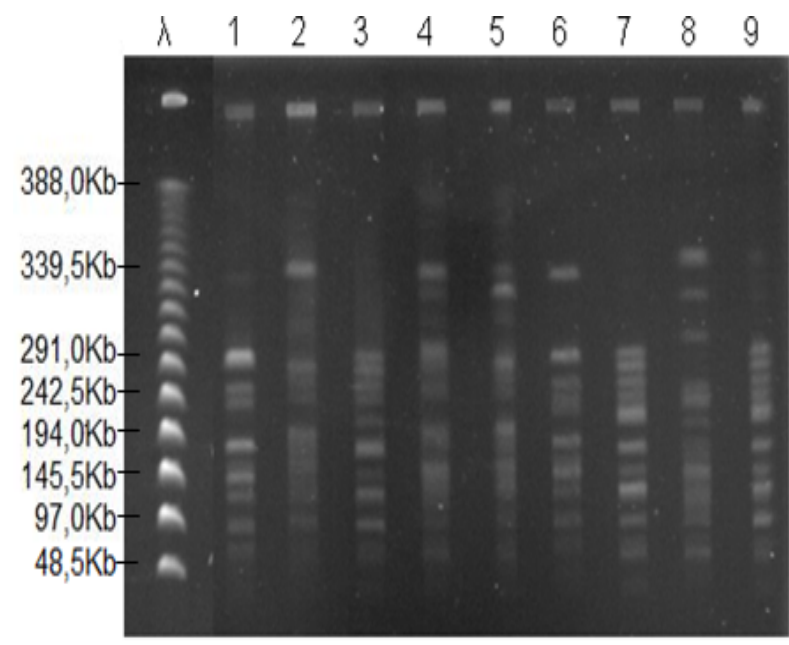

Figure 2. PFGE profiles of SmaI-digested chromosomal DNA of HLR-GE Enterococcus faecalis. $\lambda$ lambda phage DNA markers; lanes 1-9: isolates belonging to different clonal groups (lanes 1-6: isolates from HCPA; lanes 7-9: isolates from HSL. Lane 2: isolate resistant to vancomycin and teicoplanin).

\section{DISCUSSION}

In this study, we have evaluated the frequency of species, the patterns of antimicrobial resistance and the molecular epidemiology of enterococci in clinical specimens obtained from two different hospitals of the city of Porto Alegre, Brazil.

Several species of enterococci are currently recognized, but $85-95 \%$ of enterococcal infections are caused by $E$. faecalis, and 5-10\% are caused by E. faecium $(3,6,11,19)$. This study showed that E. faecalis was the most prevalent specie $(93.6 \%)$ and other species were found only in a minority of cases [E. faecium (4.4\%), E. casseliflavus (1\%), E. gallinarum $(0.5 \%)$ e E. hirae $(0.5 \%)]$. Although a few studies $(14,22)$ have documented an increase in the prevalence of E. faecium, in this study the prevalence of this specie was considerable low. This may be due to the fact that high prevalence of E. faecium is usually related to increase resistance to vancomycin which was not the case in this study.

Results of antimicrobial susceptibility tests by the disk diffusion method showed that vast the majority of the isolates $(97.5 \%)$ in this study were susceptible to ampicillin. In fact, only one E. faecalis was resistant to ampicillin as the other 4 ampicillin-resistant isolates belonged to the E.faecium species. This high susceptibility rate to ampicillin is similar to rates from other studies $(7,13,16)$ and confirm that $E$. faecalis resistant to ampicillin is also quite rare in our region $(3,8,22)$.

We found only one isolate resistant to vancomycin and teicoplanin, which was identified as E. faecalis, and this confirms that the prevalence of VRE is still very low in clinical isolates from patients with infections in our region. In fact, VRE is more frequent in studies that assess colonization of patients $(1,8)$.

The two isolates with intermediary resistance to vancomycin, E. casseliflavus and E. gallinarum, were not further investigated in this study as these species have low clinical impact and are not implicated in epidemic outbreaks and thus, have small importance for the control of intrahospital infections $(3,5,8,11,14)$.

Conversely, we found high-level resistance to streptomycin or gentamicyn in $37.4 \%$ and $23.6 \%$, respectively, while the resistance to both aminoglycosides (HLR-GE/ST) was $10.3 \%$. This finding is a cause of concern, because it may indicate a major resistance problem in our hospitals in the near future. However, the resistance to gentamycin in high levels is of more importance than the resistance in high levels to streptomycin as HLR-GE predicts 
Bender, E.A. et al.

resistance to all other aminoglycosides, except streptomycin (22, 25). Similar resistance rates of HLAR have been reported in Cuba by Quiñones et al. (20) and in Peru by Kaçmaz \& Aksoy (14). In Brazil, studies in the state of Paraná (2) and in Rio Grande do Sul (13) presented lower rates of HLAR. It is of note that a previous study performed in the same hospitals indicated a very similar HLR/GE resistance rate but a HLR/ST considerable lower (15.8\%) (6, 7).

Alternative antibiotics to treat infections by Enterococcus also showed high rates of resistance in vitro: erythromycin (62.1\% of resistance) and tetracycline (64.5\%), which makes them unsuitable for empirical antimicrobial therapy.

On the other hand, the isolates of enterococci in this study displayed moderate resistance to rifampicin (24.6\%), chloramphenicol (33\%) and ciprofloxacin (30\%) and low resistance only to nitrofurantoin $(2 \%)$. These antimicrobials may, therefore, be indicated for empirical treatment of urinary tract infection due to Enterococcus sp in our region as previously suggested (19).

The resistance to quinupristin-dalfopristin $(\mathrm{Q} / \mathrm{D})$ was $87.2 \%$, but this cannot be considered representative of this genus as we found a low resistance among E. faecium (11.1\%) and a high level among E. faecalis (91\%). In fact, it is well known that E.faecalis is intrinsically resistant to Q/D and this was confirmed in our results. However, Q/D has been used successfully to treat infections caused by $E$. faecium despite some studies describing the emergence of resistance during the therapy. $(4,17,22)$.

As demonstrated by molecular typing, there was a predominant clone among isolates of E. faecalis HLRGE/ST. As this clone was obtained from isolates of patients attending two hospitals (HCPA and HSL) during a short

time-frame period, it is possible to consider that there was an intra and inter-hospital dissemination of E. faecalis HLRGE/ST. This is the first report of a major clonal E. faecalis HLR-GE/ST spread in two hospitals of Porto Alegre although, previously, only a clone of E. faecalis HLR-GE had been reported (7). In fact, we found a considerable genetic diversity among E. faecalis HLR-GE in our study. Noteworthy, clonal dissemination of E. faecalis HLR-GE/ST has already been described in the state of Rio de Janeiro in previous years (18).

The only E. faecalis resistant to vancomycin identified in our study showed different genetic profile from the predominant clone of E. faecalis HLR-GE/ST. Therefore, we could infer that the high prevalence of this clone would not lead to selection of VRE strains in the two hospitals evaluated.

Moreover, it was possible to compare the VRE genetic profile from this study with the profile of the clonal VRE from an outbreak describe in previous years in the city of Porto Alegre (21) and they proved to be the same (data not shown). This result confirms that the previous VRE reported in Porto Alegre had not spread to hospitalized patients with infection due to enterocci.

The identification of a major clonal group in E. faecalis HLR-GE/ST, draws attention to the increasing need for control measures to avoid horizontal transmission, since the enterococci currently represent a serious problem in health institutions, especially because of the possibility of spread from healthy carriers and the lack of effective treatment options.

\section{ACKNOWLEDGEMENTS}


The authors thank to Fundação de Incentivo a Pesquisa of Hospital de Clínicas de Porto Alegre (FIPE/HCPA) and CAPES.

\section{RESUMO}

\section{Identificação, resistência antimicrobiana e caracterização genotípica de Enterococcus spp. isolados em Porto Alegre, Brasil}

Nas últimas duas décadas os membros do gênero Enterococcus emergiram como importantes patógenos nosocomiais ao redor do mundo. No presente estudo, nós avaliamos a resistência antimicrobiana e as características genotípicas de 203 Enterococcus spp. obtidos de diferentes fontes clínicas em dois hospitais de Porto Alegre, Rio Grande do Sul, Brasil. As espécies foram identificadas por testes bioquímicos convencionais e por um sistema automatizado. A diversidade genética de E. faecalis demonstrando resistência à altos níveis de aminoglicosídeos (HLAR) foi avaliada através da análise do DNA cromossômico após digestão com a enzima SmaI, seguido por eletroforese em campo pulsado. O E. faecalis foi a espécie mais freqüente $(93,6 \%)$, seguido por E. faecium (4,4\%). O perfil de resistência antimicrobiana foi: 2,5\% para ampicilina, 0,5\% para vancomicina, $0,5 \%$ para teicoplanina, 33\% para cloranfenicol, 2\% para nitrofurantoína $66,1 \%$ para eritromicina, $66,5 \%$ para tetraciclina, $24,6 \%$ para rifampicina, $30 \%$ para ciprofloxacino e $87,2 \%$ para quinupristinadalfopristina. Um total de $10,3 \%$ dos isolados apresentaram HLAR para ambos gentamicina e estreptomicina (HLR$\mathrm{ST} / \mathrm{GE}$ ), sendo $23,6 \%$ resistentes somente a gentamicina (HLR-GE) e 37,4\% somente a estreptomicina (HLR-ST). Um grupo clonal predominante foi encontrado em E. faecalis
HLR-GE/ST. A prevalência de resistência a antibióticos $\beta$ lactâmicos, e em particular aos glicopeptídeos, foi muito baixa. Entretanto, neste estudo, houve um número crescente de Enterococcus HLAR que podem estar se disseminando intra e interhospitais.

Palavras-chave: Enterococcus, resistência, HLAR, PFGE

\section{REFERENCES}

1. Bazet, C.; Blanco, J.; Seija, V.; Palácio, R. (2005). Enterococos resistentes a vancomicina. Un problema emergente en Uruguay. Rev. Med. Urug 21: 151-158.

2. Bedendo, J.; Pignatari, A.C.C. (2000). Typing of Enterococcus faecium by polymerase chain reaction and pulsed field gel electrophoresis. Braz J Med Biol Res, v. 33, p. 1269-1274.

3. Cetinkaya, Y.; Falk, P.; Mayhall, C.G. (2000). Vancomycin-Resistant Enterococci. Clin Microbiol Rev 13: 686-707.

4. Chow, J.W.; Donahedian, S.M.; Zervos, M.J. (1997). Emergence of increased resistance to quinupristin/dalfopristin during therapy for Enterococcus faecium bacteremia. Clin Infect Dis 24: 90-91.

5. CLSI - Clinical and Laboratory Standards Institute. (2007). Performance Standards for Antimicrobial Susceptibility Testing; Sixteenth Informational Supplement - M100-S17. CLSI.

6. D'Azevedo, P.A.; Dias, C.A.G.; Lemos, S.B.; Bittencourt, J.A.F.; Teixeira, L.M. (2004). Antimicrobial susceptibility among Enterococcus isolates from the city of Porto Alegre, RS, Brazil. Braz. J. Microbiol 35: 199-204.

7. D'Azevedo, P.A.; Dias, C.A.G.; Teixeira, L.M. (2006). Genetic diversity and antimicrobial resistance of enterococcal isolates from southern region of Brazil. Rev Inst Med Trop Sao Paulo 48: 11-16.

8. Deshpande, L.M.; Fritsche, T.R.; Moet, G.J.; Biedenbach, D.J.; Jones, R.N. (2007). Antimicrobial resistance and molecular epidemiology of vancomycin-resistant enterococci from North America and Europe: a report from the SENTRY antimicrobial surveillance program. Diagn Microbiol Infect Dis 58: 163-170.

9. Facklam, R.R.; Collins, M.D. (1989). Identification of Enterococcus species isolated from human infections by a conventional test scheme. J Clin Microbiol 27: 731-734.

10. Facklam, R.R.; Carvalho, M.G.; Teixeira, L. (2002). History, taxonomy, biochemical characteristics, and antibiotici susceptibility 
testing of enterococci. In: Gilmore M. S. The enterococci pathogenesis, molecular biology, and antibiotic resistance. Washington, DC: American Society for Microbiology.

11. Facklam, R.R.; Carvalho, M.G.S.; Teixeira, L.M. (2007). Enterococcus. In: Murray PR, Baron EJ, Pfaller MA, Jorgensen JH, Landry ML. Manual of Clinical Microbiology. v. $1,9^{\text {th }}$ ed. Washington, American Society for Microbiology, USA, p. 430-442.

12. Furtado, G.H.C.; Martins, S.T.; Coutinho, A.P.; Soares, G.M.M.; Wey, S.B.; Medeiros, E.A.S. (2005). Incidência de Enterococcus resistente à vancomicina em um hospital universitário no Brasil. Rev. Saúde públ 39: 41-46.

13. Hörner, R.; Liscano, M.G.H.; Maraschin, M.M.; Salla, A.; Meneghetti, B.; Forno, N.F. D.; Righi, R.A. (2005). Suscetibilidade antimicrobiana entre amostras de Enterococcus isoladas no Hospital Universitário de Santa Maria. J. Bras. Patol Med Lab, v. 41, n. 6, p. 391-395.

14. Kaçmaz, B.; Aksoy, A. (2005). Antimicrobial resistence of enterococci in Turkey. Int J Antimicrob Agents 25: 535-538.

15. Kaufmann, M.E. (1998). Pulsed-field gel electrophoresis. In: Woodford N, Johnson AP. Molecular Bacteriology, Protocols and Clinical Applications. New Jersey: Humana Press Inc, p.33-62.

16. Kobayashi, I.; Muraoka, H.; Iyoda, T.; Nishida, M.; Hasegawa, M.; Yamaguchi, K. (2004). Antimicrobial susceptibility testing of vancomycin-resistant Enterococcus by VITEK 2 system, and comparison with two NCCLS reference methods. J Med Microbiol. 53: 1229-1232.

17. Mendes, C.; Sinto, S.I.; Hsiung, A.; Oplustil, C.; Teixeira, L.; Segura, A.; Souza, D.; Barth, A.L.; Nicodemo, A.C. (2002). Atividade antimicrobiana in vitro de quinupristina/dalfopristina para cocos Grampositivos isolados de cinco centros brasileiros: resultado do estudo de vigilância L-SMART. J Bras Patol Med Lab 38: 191-197.
18. Mondino, S.B.; Castro, A.C.D.; Mondino, P.J.J.; Carvalho, M.G.S.; Silva, K.M.F.; Teixeira, L.M. (2003). Phenotypic and genotyping characterization of clinical and intestinal Enterococci isolated from inpatients and outpatients in two Brazilian Hospitals. Microb Drug Resist 9: 167-174.

19. Murray, B.E. (2000). Vancomycin-resistent enterococcal infections. New Engl J Med 342: 710-721.

20. Quiñones, D.; Goñi, P.; Rubio, M.C.; Duran, E.; Gómez-Luz, R. (2005). Enterococci spp. isoletd from Cuba: species frequency of occurrence and antimicrobial suceptibility profile, Diagn Microbiol Infect Dis., v. 51, p. 63-67.

21. Sandri, A.M. (2004). Enterococcus spp. resistente à vancomicina: tipagem molecular, caracterização clínica e associação com mortalidade. Porto Alegre, Brasil, 85p. (M.Sc. Dissertation. Programa de Pós-Graduação em Medicina. UFRGS).

22. Shepard, B.D.; Gilmore, M.S. (2002). Antibiotic-resistant enterococci: mechanisms and dynamics of drug introduction and resistance. Microb Infect 4: 215-224.

23. Tenover, F.C.; Arbeit, R.D.; Goering, R.V.; Mickelsen, P.A.; Murray, B.E.; Persing, D.H.; Swaminathan, B. (1995). Interpreting chromosomal DNA restriction patterns produced by pulsed-field gel electrophoresis: criteria for bacterial strain typing. J Clin Microbiol 33: 2233-2239.

24. Zanella, R.C.; Lima, M.J.C.; Tegani, L.S.; Hitomi, A.; Brandileone, A.C.; Palazzo, I.C.; Darini, A.L.C. (2006). Emergence of vanB phenotype-vanA genotype in vancomycin-resistant enterococci in Brazilian hospital. Braz J Microbiol 37: 117-118

25. Zarrili, R.; Tripodi, M.F.; Podolo, A.D.; Fortunato, R.; Bagattini, M.; Crispino, M.; Florio, A.; Triassi, M.; Utili, R. (2005). Molecular epidemiology of high-level aminoglycoside-resistant enterococci isolated from patients in a university hospital in southern Italy. $J$ Antimicrob Chemother 56: 827-835. 